\title{
Keaktifan Ibu dalam Kegiatan Posyandu memiliki Hubungan dengan Pertumbuhan Balita
}

\author{
Miftakhul Mai'manah'1 ${ }^{1}$ Budi Mulyadi² \\ ,2Program Studi Ilmu Keperawatan \\ Sekolah Tinggi Ilmu Kesehatan Indonesia Maju \\ Jln. Harapan Nomor 50, Lenteng Agung - Jakarta Selatan 12610 \\ Telp : (021)78894045 Email:1miftahmaimanah@gmail.com,²bemulyadi74@gmail.com
}

\begin{abstract}
Latar Belakang: Pemantauan pertumbuhan balita sangat penting dilakukan untuk mengetahui adanya gangguan pertumbuhan secara dini. Untuk mengetahui pertumbuhan tersebut, penimbangan balita setiap bulan sangat diperlukan. Penimbangan balita dilakukan di berbagai tempat seperti Posyandu, Puskesmas atau sarana pelayanan kesehatan lain

Tujuan: tujuan penelitian untuk mengetahui hubungan keaktifan ibu dalam kegiatan posyandu dengan pertumbuhan balita di Posyandu Semangka 2 Wilayah RW 05 Ciganjur Jakarta Selatan.

Metode: penelitian menggunakan desain deskriptif korelasi dengan pendekatan cross sectional. Sample penelitian berjumlah 63 responden ,menggunakan teknik purposive sampling. Instrument penelitian menggunakan kuesioner.Hasil:penelitian memperoleh keaktifan ibu yang kurang baik sebanyak 39 orang.

Hasil: Hasil uji Chi Square memperoleh nilai yang signifikan yaitu p-value sebesar 0,032 (p-value $<0,05)$.

Kesimpulan: Ada hubungan keaktifan ibu dalam kegiatan posyandu dengan pertumbuhan balita di Posyandu Semangka 2 Wilayah RW 05 Ciganjur Jakarta Selatan. Saran: Meningkatkan pengetahuan bagi ibu agar tetap aktif dalam kegiatan posyandu agar pertumbuhan balitanya selalu terpantau.
\end{abstract}

Kata Kunci: Keaktifan ibu, pertumbuhan balita

Editor: WN

Available Article

Hak Cipta:

(C)2021 Artikel ini memiliki akses terbuka dan dapat didistribusikan berdasarkan ketentuan Lisensi Atribusi Creative Commons, yang memungkinkan peng-gunaan, distribusi, dan reproduksi yang tidak dibatasi dalam media apa pun, asalkan nama penulis dan sumber asli disertakan. Karya ini dilisensikan di bawah Lisensi Creative Commons Attribution-Share Alike 4.0 Internasional.

\section{Pendahuluan}

Pada fase perkembangan manusia, akan mengalami masa pertumbuhan (growth), atau kondisi dimana akan terjadi proses pertambahan atau perkembangan ukuran, jumlah maupun dimensi dari tubuh manusia yang bersifat kuantitatif. Pertumbuhan ini meliputi sistem organ dan tingkatan sel, maupun pada tingkatan individu dimana secara fisik akan mengalami perubahan. Anak tidak hanya mengalami perubahan fisik tetapi juga struktur pada sistem organ. Contohnya ketika anak memasuki fase perkembangan otak, maka anak akan memiliki kemampuan mengingat dan kemampuan belajar yang lebih baik dan lebih cepat. Selain itu, perkembangan secara mental, dimana anak akan tumbuh dengan pemikiran yang lebih dewasa atau mampu berpikir kritis dan membedakan nilai pada suatu fenomena. ${ }^{1}$ 


\section{IJ INDONESIA JOURNAL OF Miduifery SCIENCES}

Status gizi pada balita sangat mempengaruhi tinggi badan (balita pendek). Balita pendek dikategorikan apabila seorang balita yang telah diukur tinggi badan atau panjangnya tidak masuk ke dalam kategori pertumbuhan yang seharusnya sesuai dengan usia balita. artinya hasilnya berada di bawah normal. Berdasarkan data WHO (2015), diprediksikan bahwa ada sekitar 162 juta balita yang kurang gizi dan mengalami tinggi badan abnormal atau pendek pada tahun 2015, apabila hal ini terus berlanjut maka dapat diprediksikan bahwa di tahun 2025 akan bertambah sebanya $56 \%{ }^{2}$ Masalah kesehatan masyarakat salah satunya adalah balita pendek. Di Indonesia sendiri berdasarkan data kementerian kesehatan, masih tergolong tinggi jika dibandingkan dengan prevalensi beberapa negara yang ada di Asia, misalkan dengan Thailand (16\%), Vietnam (23\%), Myanmar (35\%), dan Singapura (4\%). ${ }^{3}$ Global Nutrition Report (2014) melaporkan bahwa dari 17 negara yang memiliki masalah gisi balita (overweigh, wasting dan stunting), Indonesia masuk ke dalam salah satu negara tersebut.

Persentase status gizi balita pendek (pendek dan sangat pendek) di Indonesia Tahun 2007 yaitu 35,6\%, tahun 2010 yaitu 35,6\% atau dapat dikatakan diangka yang sama, dan 2013 adalah $37,2 \%$, artinya mengalami peningkatan jumlah penderita. Persentase tertinggi pada tahun 2013 adalah di Provinsi Nusa Tenggara Timur (51,7\%), Sulawesi Barat (48,0\%) dan Nusa Tenggara Barat (45,3\%) sedangkan persentase terendah adalah Provinsi Kepulauan Riau (26,3\%), DI Yogyakarta (27,2\%) dan DKI Jakarta (27,5\%).Menurut hasi PSG 2015, sebesar 29\% balita Indonesia termasuk kategori pendek, dengan persentase tertinggi juga di Provinsi Nusa Tenggara Timur dan Sulawesi Barat. ${ }^{4}$ Balita atau bayi dibawah lima tahun, cenderung memiliki resiko penyakit yang lebih tinggi dibandingkan dengan orang dewasa atau anak-anak. Hal tersebut didasarkan pada kondisi balita masih dalam tahap pertumbuhan. Kondisi geografis Indonesia yang berada di daerah tropis menjadi salah satu penyebab terjadinya variasi mikroorganisme predisposisi penyakit lebih meningkat. Pasien anak balita (1-4 tahun) yang obesitas di provinsi DKI Jakarta jumlahnya paling banyak bila dibandingkan dengan provinsi lain di Indonesia. Untuk jenis pelayanan rawat inap berjenis kelamin laki-laki (7 orang) dan perempuan (5 orang). Sedangkan untuk jenis pelayanan rawat jalan provinsi jawa tengah menempati jumlah anak balita yang obesitas terbanyak baik jenis kelamin laki-laki (11 orang) maupun perempuan (5orang), diikuti provinsi Sumatera Selatan anak baita yang obesitas berjenis kelamin lakilaki (10 orang). ${ }^{5}$

Upaya untuk meningkatkan kualitas anak di antaranya dengan melakukan suatu program untuk memantau pertumbuhan dan perkembangan bagi sang anak. Salah satu cara yang dapat digunakan untuk mengetahui atau mendapatkan informasi tentang gangguan pertumbuhan pada anak yaitu dengan melakukan pemantauan pertumbuhan secara dini. Contohnya dengan melakukan pengukuran berat badan/ penimbangan bayi setiap bulan. Akan tetapi, program pertumbuhan dan perkembangan bagi anak ternyata di nilai masih kurang. Ibu sebagai pengasuh terdekat anak harus mengetahui lebih banyak proses tumbuh kembang anak serta faktor-faktor yang mempengaruhi proses itu. Pengertian, kesadaran, dan kemampuan ibu dalam menangani merupakan faktor yang menentukan dalam pembentukan kualitas anak. Agar orang tua mampu melaksanakan fungsinya dengan baik, maka orang tua perlu memahami tingkatan perkembangan anak, menilai pertumbuhan dan mempengaruhi motivasi yang kuat untuk memajukan tumbuh kembang anak. ${ }^{6}$ Berdasarkan keterangan dari petugas dan beberapa responden di posyandu semangka 2, didapatkan gambaran umum tentang keaktifan ibu dalam kegiatan posyandu masih kurang.Hal ini ditandai banyaknya jumlah ibu yang tidak datang ke posyandu pada saat waktu yang telah di tetapkan.Ibu yang aktif dalam kegiatan posyandu pertumbuhan balitanya dapat terpantau, sedangkan ibu yang tidak aktif pertumbuhan balitanya tidak dapat terpantau. Berdasarkan fenomena tersebut diatas maka peneliti akan melakukanpenelitian tentang "Hubungan Keaktifan ibu dalam Kegiatan posyandu dengan Pertumbuhan Balita di Posyandu Semangka 2 wilayah RW 05 Ciganjur Jakarta Selatan”.

\section{Metode}

Metode yang peneliti gunakan dalam penelitian ini adalah metode korelasi dengan pendekatan cross-sectional.7 Pada penelitian ini penulis hanya melakukan pengukuran pada responden yang memiliki balita di Posyandu Semangka 2 Wilayah RW 05 Ciganjur Jakarta selatan. 


\section{IJ INDONESIA JOURNAL OF Midwifery SCIENCES}

Populasi merupakan total jumlah dari objek penelitian, dalam penelitian ini, peneliti mengambil populasi ibu yang memiliki balita di wilayah RW 05 Ciganjur Jakarta Selatan yang dengan jumlah 134 populasi berdsarkan data Posyandu, Adapun yang menjadi sampel dalam penelitian ini yaitu sebanyak 63 orang yang memnuhi kriteria inklusi penelitian. Sampel diartikan sebagai jumlah responden atau subjek yang dapat mewakili populasi. ${ }^{8}$ Teknik pengambilan sampel yaitu Purposive Sampling, teknik ini didasarkan pada pertimbangan peneliti dengan memperhatikan sifat populasi yang ada dan sampel dapat memenuhi nilai populasi atau kareakteritik populasi yang ada.

Instrument atau alat ukur yang peneliti gunakan yaitu data yang bersifat primer maupun data sekunder. Data sekunder di dapatkan dari jumlah balita yang terdaftar di posyandu Semangka 2 Wilayah RW 05 Ciganjur Jakarta Selatan.Pengumpulan data dilakukan dengan menggunakan kuesioner dan KMS untuk mendapatkan jawaban dari penelitian yang dilakukan. Proses analisa data dalam penelitian ini dibagi menjadi 2 yaitu analisa Univariat yang bertujuan untuk menjelaskan karakteristik setiap variable penelitian dan analisa Bivariat bertujuan untuk menjelaskan hipotesis hubungan variable keaktifan ibu dalam kegiatan posyandu dengan variable pertumbuhan balita. Uji chi Square dilakukan untuk mengetahui antara dua variable yaitu variable independen dan dependen terdapat hubungan atau tidak dengan ketentuan nilai $p$ value $<0.05$.

Hasil

Tabel 1. Gambaran karakteristik

\begin{tabular}{ccc}
\hline $\begin{array}{c}\text { Jenis Kelamin } \\
\text { Anak }\end{array}$ & Frekuensi & Presentase \\
\hline Laki-Laki & 32 & $50,8 \%$ \\
\hline Perempuan & 31 & $49,2 \%$ \\
\hline Total & $\mathbf{6 3}$ & $\mathbf{1 0 0 \%}$ \\
\hline
\end{tabular}

berjenis kelamin laki-laki yaitu sebanyak 32 responden dengan jumlah presentase $50,8 \%$ dan 31 responden perempuan dengan jumlah presentase $49,2 \%$.

Tabel 2. Distribusi frekuensi Pekerjaan Responden di Posyandu Semangka 2 ( $\mathrm{n}=63$ ).

\begin{tabular}{lcc}
\hline Pekerjaan & Frekuensi & Presentasi \\
\hline Ibu Rumah Tangga & 51 & $81 \%$ \\
\hline Wirausaha & 4 & $6,3 \%$ \\
\hline Guru & 2 & $3,2 \%$ \\
\hline Karyawan & 6 & $9,5 \%$ \\
\hline Total & $\mathbf{6 3}$ & $\mathbf{1 0 0 \%}$ \\
\hline
\end{tabular}

Berdasarkan tabel diatas dapat disimpulkan bahwa distribusi frekuensi pekerjaan responden ibu rumah tangga, wirausaha, guru, karyawan, jumlah responden terbanyak adalah dari kalangan ibu rumah tangga yang berjumlah 51 orang dengan presentase sebesar $81 \%$.

Analisis deskriptif frekuensi Pendidikan responden dapat dilihat pada tabel berikut ini :

Tabel 3. Distribusi frekuensi Pendidikan Responden di Posyandu Semangka 2 ( $n=63$ ).

\begin{tabular}{ccc}
\hline Pendidikan & Frekuensi & Presentase \\
\hline SMP & 5 & $7,9 \%$ \\
\hline SMK & 50 & $79,4 \%$ \\
\hline S1 & 8 & $12,7 \%$ \\
\hline Total & $\mathbf{6 3}$ & $\mathbf{1 0 0 \%}$ \\
\hline
\end{tabular}




\section{J INDONESIA JOURNAL \\ of Miduifery sciences}

Berdasarkan tabel diatas dapat di simpulkan bahwa distribusi frekuensi responden pendidikan adalah SMP, SMK, S1, dan jumlah responden terbanyak adalah SMK dengan jumlah 50 serta presentase sebesar $79,4 \%$.

Tabel 4. Distribusi frekuensi Jumlah Anak Responden di Posyandu Semangka 2 ( $n=63$ ).

\begin{tabular}{ccl}
\hline Jumlah Anak & Frekuensi & Presentase \\
\hline 1 & 13 & $44,2 \%$ \\
\hline 2 & 31 & $28,4 \%$ \\
\hline 3 & 16 & $5,3 \%$ \\
\hline 4 & 3 & $4,2 \%$ \\
\hline Total & $\mathbf{6 3}$ & $\mathbf{1 0 0} \%$ \\
\hline
\end{tabular}

Sumber : Data Primer 2018

Berdasarkan tabel diatas dapat di simpulkan bahwa distribusi frekuensi responden jumlah anak adalah 1, 2, 3, 4 dan jumlah responden terbanyak adalah 2 dengan jumlah 31 serta presentase sebesar $28 \%$.

Table 5. Distribusi frekuensi Usia Responden di Posyandu Semangka 2 ( $\mathrm{n}=63)$

\begin{tabular}{ccc}
\hline Usia & Frekuensi & Presentase \\
\hline $21-32$ & 42 & $66,7 \%$ \\
\hline $32-43$ & 21 & $33,3 \%$ \\
\hline Total & $\mathbf{6 3}$ & $\mathbf{1 0 0 \%}$ \\
\hline
\end{tabular}

Berdasarkan tabel diatas pada penelitian ini usia yang dijadikan sampel penelitian adalah 2132 dan 32-43 tahun, jumlah terbanyak adalah usia 21-32 tahun dengan jumlah 42 responden serta presentase sebesar $66,7 \%$.

Tabel 6. Distribusi Gambaran Keaktifan Ibu dalam Kegiatan Posyandu Responden di Posyandu Semangka 2.

\begin{tabular}{ccc}
\hline $\begin{array}{c}\text { Keaktifan Ibu dalam Kegiatan } \\
\text { Posyandu }\end{array}$ & Frekuensi & Persentase (\%) \\
\hline Kurang Baik & 39 & 61,9 \\
\hline Baik & 24 & 38,0 \\
\hline Total & 63 & 100 \\
\hline
\end{tabular}

Berdasarkan tabel diatas menunjukkan keaktifan ibu dalam kegiatan posyandu di Posyandu Semangka 2 61,9\% memiliki keaktifan ibu dalam kegiatan posyandu kurang baik dan memiliki keaktifan ibu dalam kegiatan posyandu $38,0 \%$ baik. 


\section{IJ INDONESIA JOURNAL \\ OF Miduifery SCIENCES}

Tabel 7. Distribusi Gambaran Pertumbuhan Balita Responden di Posyandu Semangka 2.

\begin{tabular}{ccc}
\hline Pertumbuhan Balita & Frekuensi & Presentase \\
\hline Sangat Pendek & 26 & $41,2 \%$ \\
\hline Pendek & 13 & $20,6 \%$ \\
\hline Normal & 12 & $19,0 \%$ \\
\hline Tinggi & 12 & $19,0 \%$ \\
\hline Total & $\mathbf{6 3}$ & $\mathbf{1 0 0 \%}$ \\
\hline
\end{tabular}

Sumber : Data Primer 2018

Analisis deskriptif hubungan keaktifan ibu dengan pertumbuhan balita dapat dilihat pada tabel berikut ini: Tabel 8. Hubungan Keaktifan Ibu dalam Kegiatan Posyandu dengan Pertumbuhan Balita di Posyandu Semangka 2 Wilayah RW 05 Ciganjur Jakarta Selatan.

\begin{tabular}{|c|c|c|c|c|c|c|c|c|c|c|c|}
\hline \multirow{3}{*}{$\begin{array}{c}\text { Keaktifan } \\
\text { Ibu }\end{array}$} & \multicolumn{8}{|c|}{ Pertumbuha Balita } & \multicolumn{2}{|c|}{ Total } & \multirow{3}{*}{$\begin{array}{c}\text { P- } \\
\text { Value }\end{array}$} \\
\hline & \multicolumn{2}{|c|}{ Sangat pendek } & \multicolumn{2}{|c|}{ Pendek } & \multicolumn{2}{|c|}{ Normal } & \multicolumn{2}{|c|}{ Tinggi } & \multirow[b]{2}{*}{$\mathrm{F}$} & \multirow[b]{2}{*}{$\%$} & \\
\hline & $\mathrm{F}$ & $\%$ & $\mathrm{~F}$ & $\%$ & $\mathrm{~F}$ & $\%$ & $\mathrm{~F}$ & $\%$ & & & \\
\hline $\begin{array}{c}\text { Kurang } \\
\text { baik }\end{array}$ & 20 & 51,3 & 7 & 17,9 & 6 & 15,4 & 6 & 15,4 & 39 & 100 & \multirow[t]{3}{*}{0,032} \\
\hline Baik & 6 & 25,0 & 6 & 25,0 & 6 & 25,0 & 6 & 25,0 & 24 & 100 & \\
\hline Total & 26 & 41,3 & 13 & 20,6 & 12 & 19,0 & 12 & 19,0 & 63 & 100 & \\
\hline
\end{tabular}

Sumber : Data Primer 2018

berdasarkan table diatas dapat di lihat dari 63 responden, bahwa sebagian besar responden memiliki keaktifan ibu terhadap pertumbuhan balita kurang baik sebesar 20 orang $(51,3 \%)$ dari total sebanyak 63 responden. Hasil penelitian menggunakan software penelitian di dapatkan nilai Asymp.Sig 0,032 yang artinya ada hubungan yang cukup signifikan antara kedua variabel tersebut yaitu kaektifan ibu dalam kegiatan posyandu dengan pertumbuhan balita di Posyandu Semangka 2 Wilayah RW 05 Ciganjur Jakarta Selatan, karena nilai sig $p$ yang didapatkan $\leq 0,05$.

\section{Pembahasan}

\section{Gambaran Keaktifan Ibu dalam Kegiatan Posyandu}

Berdasarkan hasil yang sudah di dapat maka diketahui bahwa sebagian besar keaktifan ibu dalam kegiatan posyandu di Posyandu Semangka 2 61,9\% memiliki keaktifan ibu dalam kegiatan posyandu yang kurang baik dan memiliki keaktifan ibu dalam kegiatan posyandu 38,0\% yang baik. Dengan hasil presentasi tersebut dapat diketahui jika usia bisa mempengaruhi keaktifan ibu dalam kegiatan posyandu dengan pertumbuhan balita. Berdasarkan tabel diatas bahwa pertumbuhan balita di Posyandu Semangka 2 dari 63 responden terdapat $26(41,2 \%)$ balita sangat pendek, $13(20,6 \%)$ persen balita pendek, $12(19,0 \%)$ balita normal, dan 12 (19,0\%) balita tinggi, dengan mengukur Zscorenya tinggi badan / usia mengalami status gizi yang normal sebanyak 12 responden.

Hal ini sesuai dengan penelitian Febry Frekuensi kunjungan balita ke Posyandu semakin berkurang dengan semakin meningkatnya umur anak. Sebagai gambaran proporsi anak 6-11 bulan yang ditimbang di Posyandu 91,3\%, pada anak usia 12-23 bulan turun menjadi 83,6\%, dan pada usia 24-35 bulan turun menjadi $73,3 \% .{ }^{9}$ Menurut peneliti terdapat hubungan antara keaktifan ibu dalam 


\section{IJ INDONESIA JOURNAL OF Miduifery SCIENCES}

kegiatan posyandu dengan pertumbuhan balita, karena kurangnya kehadiran ibu ke posyandu berpengaruh terhadap pemantauan pertumbuhan balitanya.

\section{Gambaran Pertumbuhan Balita}

Berdasarkan hasil yang sudah di dapat maka diketahui bahwa sebagian besar pertumbuhan balita di Posyandu Semangka 2 dari 63 responden terdapat $26(41,3 \%)$ balita sangat pendek, 13 $(20,3 \%)$ persen balita pendek, $12(19,0 \%)$ balita normal, dan $12(19,0 \%)$ balita tinggi, dengan mengukur Z-scorenya tinggi badan / usia mengalami status gizi yang normal sebanyak 12 responden. Hal ini dapat diketahui jika usia bisa mempengaruhi keaktifan ibu dalam kegiatan posyandu dengan pertumbuhan balita. Hal ini sesuai dengan penelitian Suharidewi (2017) Status gizi anak menurut $\mathrm{BB} / \mathrm{TB}$ yang tergolong gizi kurang $40 \%$, gizi normal $43,5 \%$, dan gizi lebih $16,5 \%$. Status gizi menurut TB/U anak yang pendek sejumlah 11 anak (12,9\%) dan yang normal 74 anak $(87,1 \%)$ Menurut peneliti masalah pertumbuhan balita sangat penting untuk di perhatikan, karena masalah pertumbuhan dapat mempengaruhi kehidupan balita dimasa yang akan datang.

\section{Hubungan Keaktifan Ibu dalam Kegiatan Posyandu dengan Pertumbuhan Balita}

Berdasarkan hasil yang di dapat, menunjukan bahwa setelah dilakukan uji chi square didapatkanp-value 0.032 yang berarti $\mathrm{H}_{\mathrm{a}}$ diterima karena nilai $p$-value $\leq 0,05$. Sehingga dapat dikatakan ada hubungan antaraKeaktifan Ibu dalam Kegiatan Posyandu dengan Pertumbuhan Balita di Posyandu Semangka 2 Wilayah RW 05 Ciganjur Jakarta Selatan. Ibu yang memiliki balita dinilai masih kurang dalam partisipasinya untuk membawa anaknya ke layanan posyandu. Selain itu, tingkat pengetahuan ibu tentang KMS juga masih rendah, mereka hanya menggunakan sebagai alat untuk mencatat berat badan, bukan sebagai alat untuk memantau pertumbuhan dan perkembangan anak. Bahkan beberapa diantaranya belum memiliki KMS. ${ }^{8}$ Menurut peneliti hasil dari penelitian keaktifan ibu dalam kegiatan posyandu dengan pertumbuhan balita tergambar bagaimana keaktifan ibu dan pertumbuhan balita.Pada penelitian ini di dapatkan keaktifan ibu yang kurang baik dapat mempengaruhi pertumbuhan balita yang kurang terpantau dan kurang baik pertumbuhannya.Seharusnya ibu harus lebih rajin untuk mengunjungi posyandu agar pertumbuhan balitanya selalu terpantau.

\section{Kesimpulan}

Hasil penelitian menujukkan bahwa secara umum terdapat hubungan antara keaktifan ibu dalam kegiatan posyandu dengan pertumbuhan balita di Posyandu.Hasil penelitian ini menunjukkan keaktifan ibu dalam kegiatan posyandu memiliki kecenderungan kurang baik. Hal ini berhubungan dengan pekerjaan, pendidikan dan usia ibu yang membuat ibu malas untuk datang ke posyandu. Hal ini menjadi salah satu kendala dalam pertumbuhan balita yang kurang baik karena ibu kurang aktif dalam memeriksakan pertumbuhan balitanya.

\section{Konflik Kepentingan}

Penelitian ini tidak ada konflik kepentingan apapun baik secara individu maupun organisasi

\section{Ucapan Terima Kasih}

Terimakasih kepada semua responden yang telah berkontribusi pada penelitian ini

\section{Pendanaan}

Sumber pendanaan pada penelitian ini adalah individu.

\section{References}

1. Soetjiningsih, G. R. Tumbuh Kembang Anak Edisi 2. Jakarta: Penerbit Buku Kedokteran EGC. (2013). 


\section{IJ INDONESIA JOURNAL OF Miduifery SCIENCES}

2. RI, K. K. Riset Kesehatan Dasar Riskesdas, 209-223. (2013).

3. RI, K. K. Kondisi Pencapaian Program Kesehatan Anak Indonesia. Infodatin, 2-5. (2014).

4. RI, K. K. Situasi Balita Pendek. Infodatin, 1- 4. (2016).

5. RI, K. K. Riset Kesehatan Dasar. Riskesdas, 209-223. (2013).

6. Ai Yayeh Rukiyah, L. Y. Asuhan Neonatus Bayi Anak dan Balita, edisi revisi. Jakarta: CV Trans Info Media. (2013).

7. Devi, M. Analisis Faktor-faktor yang Berpengaruh terhadap Status Gizi Balita di Pedesaan. Teknologi dan Kejuruan, 186-189. (2010).

8. Febry, F. Pemantauan Pertumbuhan Balita di Posyandu. Jurnal Ilmu Kesehatan Masyarakat, 167. (2012).

9. Gunawan,G. F.R. Hubungan Status Gizi dan Perkembangan Anak Usia 1-2 Tahun. Sari Pediatri, 143-145. (2011).

10. I Gusti Agung, T. S. Gambaran Satus Gizi pada Anak TK di Wilayah Kerja UPT Kesmas Blahabatu II Kabupaten Ginayar Tahun 2015. E-JUNAL Medika vol 6 no 6, 1-6. (2017).

11. INDONESIA, U. Gizi Ibu dan Anak. Ringkasan Kajian Gizi, 1-3. (2012).

12. Lina Safarina, M. B. Hubungan Pengetahuan Ibu dalam Pemanfaatan Program Posyandu dengan Status Gizi Balita di Posyandu Bougenville Kota Cimahi Selatan Tahun 2017. Jurnal Kesehatan Kartika Vol. 12 No, 2, (2017).

13. Merry Lanoh, S. S. Hubungan Pemanfaatan Posyandu dengan Status Gizi Balita di Wilayah Kerja Puskesmas Ranotana Weru Kota Manado. eJounal Keperawatan (e-kep) vol 3 no 2, (2015).

14. Merryana Adrini, B. W. Peranan Gizi dalam Siklus Kehidupan. Jakarta: Prenada Media Group. (2016).

15. Putri, K. M. Hubungan antara Pengetahuan dengan Sikap ibu tentang Pemantauan Pertumbuhan Bayi 0-1 Tahun di Puskesmas Tanjung Pinang Kota Jambi Tahun 2016. Menara Ilmu vol XII no 80, 78-83. 2018. 